\title{
Estudo Experimental do Emprego do Resíduo de Construção e Demolição em Solo-Cimento
}

\author{
Viana, C. B. \\ Escola Politécnica de Pernambuco \\ Universidade de Pernambuco \\ 50.720-001 - Recife, Brasil \\ cybelle.viana@yahoo.com.br
}

\author{
Lafayette, K. P. V. \\ Escola Politécnica de Pernambuco \\ Universidade de Pernambuco \\ 50.720-001 - Recife, Brasil
}

Resumo A necessidade de preservação ambiental e a tendência de escassez dos recursos naturais, associada a uma geração exacerbada de Resíduos da Construção e Demolição, fazem com que a construção civil adquira novos conceitos e soluções técnicas visando a sustentabilidade de suas atividades. Neste trabalho são apresentados resultados de ensaios de laboratório, através dos quais se objetivou avaliar a possibilidade de aproveitamento dos resíduos de concreto na confecção de tijolos prensados de solocimento. Foram realizados ensaios de caracterização do solo utilizado, das composições desse solo com resíduos de concreto e das misturas de solo-cimento produzidas com essas composições. Conforme resultado de ensaios realizados em corpos-de-prova cilíndricos, verificou-se que adição dos residuos proporcionou melhorias nas propriedades mecânicas do solo-cimento, favorecendo a redução do consumo de cimento, do custo de produção, além de contribuir no sentido de reduzir o volume de material descartado na natureza

Palavras-chave: Resíduos da Construção e Demolição. Tijolos de Solo-Cimento. Desenvolvimento Sustentável.

\footnotetext{
Abstract The need for environmental preservation and the tendency of natural resource scarcity, coupled with na exaggerated generation of Construction and Demolition Waste, cause the building to acquire new concepts and technical solutions for the sustainability of their activities. This paper presents results of laboratory tests, through which it aimed to evaluate the possibility of recovery of waste in the manufacture of concrete bricks pressed soil-cement. Assays were performed to characterize the soil used, the compositions of soil and concrete waste soil-cement mixtures produced with these compositions. As a result of tests on body-cylinder specimens, it was found that the residue provided impro ements in the mechanical properties of soil cement, favoring the reduction in cement consumption, production cost, and contribute towards reducing the volume of discarded material in nature.
} 


\section{Introdução}

A partir da década de 80, o grande acúmulo de resíduos se transformou em um grave problema urbano, com gerenciamento oneroso, causado pela intensa industrialização, advento de novas tecnologias, crescimento populacional e aumento de pessoas em centros urbanos. O problema se caracteriza por escassez de área para disposição dos resíduos, causadas pela ocupação e valorização de áreas urbanas, problemas de saneamento público e contaminação ambiental. (JOHN, 2000) [1].

Atualmente, a disposição indiscriminada dos resíduos da construção em aterros ou em bota-foras, vem recebendo maior preocupação em relação ao meio ambiente e a qualidade de vida das cidades. Nesse contexto, o desperdício na construção civil vem sendo combatido com a qualificação da mão-de-obra, maior controle na aplicação dos materiais e projetos executivos melhor detalhados. Este pequeno avanço, no entanto, não torna inevitável a geração de entulhos.

A fabricação de tijolos prensados de solo-cimento com adição de RCD pode contribuir para reduzir o volume de materiais descartados na natureza, além de diminuir a exploração dos recursos naturais e contribuir com o seqüestro do carbono. Na produção de tijolos de soloci ento são utilizados os seguintes materiais: solo, cimento e água. As vantagens da utilização dos tijolos de solo-cimento vão desde a fabricação até sua utilização no canteiro de obras.

Neste trabalho será analisada a viabilidade da aplicação do resíduo de concreto reciclado como agregado no compósito solo-cimento. Objetiva-se com isso melhorar a qualidade dos tijolos de solo-cimento e, consequentemente, reduzir os custos e contribuir para a sustentabilidade do planeta.

\section{Solo-Cimento}

Segundo a ABCP (1999) [2], o solo-cimento é o produto resultante da mistura íntima de solo, cimento portland e água que, compactados na umidade ótima e sob a máxima massa específica seca, em proporções previamente estabelecidas, adquire resistência e durabilidade através das reações de hidratação do cimento. Os principais fatores que afetam a propriedades do solo-cimento são: tipo de solo, teor do cimento, teor de umidade, compactação e homogeneidade da mistura, além da idade e do processo de cura.

A conceituação do solo-cimento teve origem em Sallsburg no ano de 1917, entretanto, havia poucos relatos até
1932, quando se teve notícia dos primeiros trabalhos cientificamente controlados, como por exemplo, a pavimentação de $17.000 \mathrm{~m}^{2}$ em Johnsonville, Carolina do Sul, EUA (ANDRADE FILHO, 1989) [3]. O interesse pelo assunto no Brasil se deu a partir de 1936, através da ABCP - Associação Brasileira de Cimento Portland, que regulamentou e pesquisou sua aplicação. Segundo Ferraz (2004) [4], o emprego deste material em edificações foi iniciado no Brasil em 1948, com a construção das casas do Vale Florido, na Fazenda Inglesa, em Petrópolis - RJ. Desde então, a experiência brasileira vem sendo bastante ampliada, com aplicação de novas técnicas construtivas, avanços na tecnologia dos materiais e aprimoramento dos equipamentos de produção.

Segantini (2000) [5] afirma que, quanto a granulometria, os solos arenosos são mais apropriados para a confecção do solo-cimento. A existência de grãos de areia grossa e de pedregulhos é altamente benéfica, pois são materiais inertes com função apenas de enchimento. Isso favorece a liberação de quantidades maiores de cimento para aglomerar os grãos menores. Os solos devem também ter um teor mínimo da fração fina, pois a resistência inicial do solocimento é devida à coesão da fração fina compactada.

De acordo com ABCP (1999) [2], a dosagem do solocimento deve ser feita por meio de ensaios de laboratório, passando pela análise e interpretação dos resultados com base em critérios pré-estabelecidos. O resultado final consiste na fixação de três parâmetros: quantidade de cimento, quantidade de água e massa específica aparente seca máxima. Os dois últimos sofrem pequenas oscilações em função das variações que ocorrem nas características do solo. Assim, o objetivo da dosagem passou a ser somente a fixação da quantidade adequada de cimento, de acordo com tabela 1 .

Tabela 1. Teores de Cimento (ABNT, 1999).

\begin{tabular}{|c|c|}
\hline Classificação HRB & Teor de Cimento $(\%)$ \\
\hline Ala & 5 \\
\hline A1b & 6 \\
\hline A2 & 7 \\
\hline A3 & 8 \\
\hline A4 & 10 \\
\hline A5 & 10 \\
\hline A6 & 12 \\
\hline A7 & 13 \\
\hline
\end{tabular}

\section{Desenvolvimento Sustentável}


A adoção de uma política de incentivo para o reaproveitamento dos bens minerais descartados pelas obras civis pode reduzir a quantidade de minerais extraídos das jazidas e, consequentemente, diminuir o impacto ambiental por meio da reutilização e da reciclagem dos rejeitos minerais.

O relatório da Comissão Mundial sobre o Meio Ambiente e Desenvolvimento, constituída pela Organização das Nações unidas - ONU, divulgado em 1987 com o título de Nosso Futuro Comum ou Relatório Brundtland, representou um marco no enfrentamento da questão ambiental, ao propor a perspectiva de busca do chamado desenvolvimento sustentável, ou seja, um desenvolvimento que permita à humanidade "usufruir os recursos naturais sem comprometer a possibilidade de que as gerações futuras também possam fazê-lo" (BITAR, 1999) [6]

A necessidade de preservação ambiental e a tendência de escassez dos recursos naturais fazem com que a construção civil adquira novos conceitos e soluções técnicas visando a sustentabilidade de suas atividades. Neste contexto, o aproveitamento dos resíduos de construção e demolição (RCD) destaca-se como alternativa alinhada a estes novos conceitos, buscando valorizar os materiais descartados nas obras de engenharia, atribuindo-lhes a condição de material nobre, em vez de simplesmente lançá-los na natureza (FERRAZ, 2004) [4].

A Resolução CONAMA 307, aprovada em 2002 [7] criou instrumentos para a superação dos problemas gerados pelos resíduos de construção e demolição, definindo responsabilidade e deveres e abrindo caminho para o preparo de normas técnicas tanto para o correto manejo dos resíduos como para seu uso pós-reciclagem. A resolução impõe aos geradores a obrigatoriedade da redução, reutilização e reciclagem dos resíduos. Mas, diante das características diversas destes geradores, foi definida, para Municípios e Distrito Federal, a necessidade de desenvolverem e programarem Planos Integrados de Gerenciamento que possibilitem a expressão das responsabilidades dos geradores, correspondentes à sua diversidade (PINTO, 2004) [8].

\section{Materiais e Métodos}

\subsection{Materiais}

Neste trabalho foram utilizados os seguintes materiais:

\subsubsection{Solo}

O Solo utilizado neste trabalho foi coletado na Região Oeste do Estado de Pernambuco, mais especificamente, no município de Buíque. Trata-se de um solo A3, segundo a classificação HRB - Higway Research Board.

\subsubsection{Resíduo de Concreto}

Os resíduos de concreto foram coletados em caçambas coletoras de entulhos existentes em canteiros de obras em Recife-PE. A amostragem de RCD ocorreu em um período de 02 dias. Foram coletados aproximadamente $500 \mathrm{Kg}$ de material de acordo com a norma técnica NBR 7216 "Amostragem de agregados" (ABNT, 1982) [9]. Ao término da coleta, as amostras foram exaustivamente separadas de acordo com os constituintes para realização da composição gravimétrica e em seguida realizar o beneficiamento (Figura 1). Após esta etapa, a amostra foi homogeneizada em quatro partes, aproximadamente iguais, onde a quantidade era suficiente para atender a todas as etapas da pesquisa, tanto para a caracterização física como para as análises tecnológicas subseqüientes.

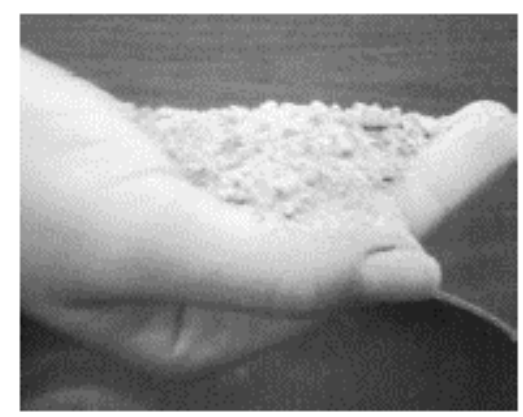

Fig 1. Resíduo de concreto após o processo de britagem.

\subsubsection{Cimento}

Foi utilizado o cimento CP II E 32, da marca Nassau, já que é um cimento composto, com adições normalizadas, para uso e aplicação geral, em que não há necessidade de resistência elevada nas primeiras idades.

\subsection{3. Água}

Utilizou-se a água potável proveniente da rede pública de abastecimento.

\subsection{Caracterização das Misturas Resí- duo/Solo}

A viabilidade técnica e econômica da aplicação do resíduo como constituinte de compósito solo-cimento está condicionada a capacidade de se utilizar um volume expressivo de resíduo. A caracterização das misturas se deu pela determinação da massa específica dos grãos, de 
acordo com a norma NBR 6508 "Solo: determinação da massa específica" (ABNT, 1984) [10], pela análise granulométrica, de acordo com a NBR 7181 "Solo: análise granulométrica" (ABNT, 1984) [11], pela determinação dos limites de consistência, NBR 6459 "Solo: determinação do limite de plasticidade" (ABNT, 1984) [12] e NBR 7180 "Solo: determinação do limite de plasticidade" (ABNT, 1984) [13] e pelo estudo de compactação NBR 7182 "Solo: Ensaio de compactação" (ABNT, 1986) [14].

$\mathrm{Na}$ composição do solo-cimento, foram estudadas dosagens compostas por solo natural, solo $+25 \%$ de RCD e solo $+50 \%$ de RCD em relação à massa de solo. Para cada uma dessas composições, o teor de cimento utilizado foi de $8 \%$ em relação à massa da mistura solo-resíduo, pois esse é o teor indicado pela ABCP para solos A3. Foram moldados dois corpos-deprova cilíndricos referentes a cada traço estudado (solo $+8 \%$ de cimento, solo $+8 \%$ de cimento $+25 \%$ de RCD e solo $+8 \%$ de cimento $+50 \%$ de $\mathrm{RCD})$. Os corpos-de-prova cilíndricos serviram para avaliar o comportamento da resistência à compressão simples de acordo com a norma técnica NBR 12025 "Solo-Cimento: Ensaio de compressão simples de corpos-de-prova cilíndricos" (ABNT, 1990) [15]. Depois de moldados, os corpos-de-prova foram transferidos para câmara úmida do Laboratório de Materiais de Construção da UPE (Figura 2).

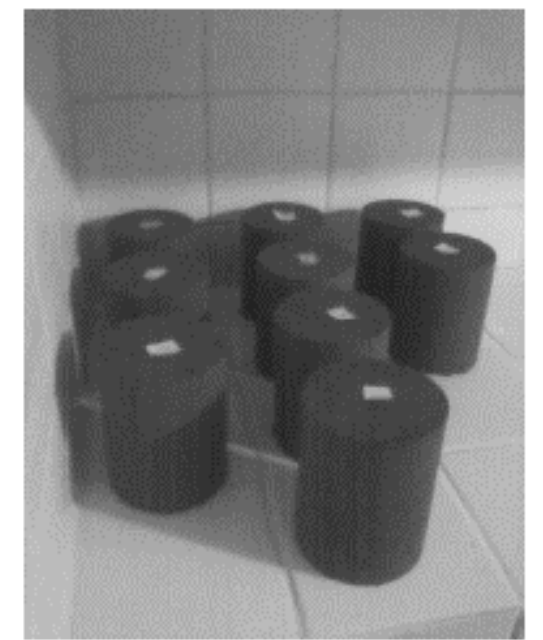

Fig 2. Corpos-de-prova cilíndricos na câmara úmida.

\section{Resultados e discussões}

\subsection{Composição Gravimétrica do RCD}

A Figura 3 apresenta o percentual de cada material presente na amostra de RCD na fase de estrutura de acordo com a separação tátil-visual realizada.

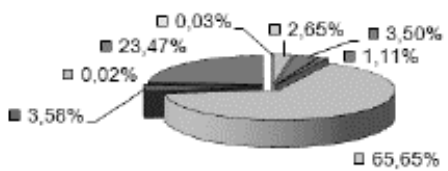

\begin{tabular}{|c|c|c|}
\hline वMIÚDO & 口TIJOLOS CERÅMICOS & DARGAMASSA \\
\hline QCONCRETO & GCONCRETO ARMADO & DSOLO \\
\hline IMISTO & DOUTROS & \\
\hline
\end{tabular}

Fig 3. Composição Gravimétrica do RCD.

De acordo com a figura acima, a participação do material miúdo (Æ $<4,8 \mathrm{~mm}$ ), do tijolo e da argamassa da amostra foram de $2,65 \%, 3,50 \%$ e $1,11 \%$, respectivamente. Podese observar também a presença de materiais como papel, plástico, madeira, vidro, isopor e metal, os quais foram chamados de "outros" cuja percentagem corresponde apenas a $0,03 \%$. Este tipo de resíduo foi desprezado na realização do beneficiamento, atendendo ao requisito estabelecido pela NBR 15115 "Agregados reciclados de resíduos sólidos da construção civil - execução de camadas de pavimentação (ABNT, 2004) [16].

\subsection{Composição Granulométrica}

A Figura 4 apresenta as curvas granulométricas do solo natural, do RCD e das misturas destes.

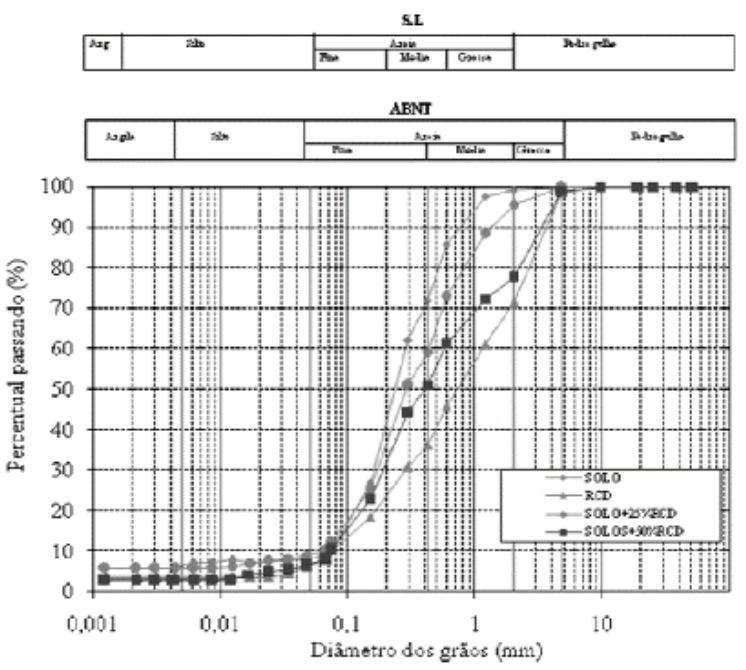

Fig 4. Curvas granulométricas do solo natural, do RCD e das composições de solo com resíduo.

A caracterização das misturas com as proporções especificadas permitiram identificar o material como predominantemente arenoso. Os resultados obtidos pela caracterização física estão apresentados na Tabela 2. 
Tabela 2. Composição granulométrica das amostras.

\begin{tabular}{|c|c|c|c|c|}
\hline Amostra & $\begin{array}{c}\text { Argila } \\
(\%)\end{array}$ & $\begin{array}{c}\text { Silte } \\
(\%)\end{array}$ & $\begin{array}{c}\text { Areia } \\
(\boldsymbol{\%})\end{array}$ & $\begin{array}{c}\text { Pedregulho } \\
(\boldsymbol{\%})\end{array}$ \\
\hline Solo & $6,20 \%$ & $1,83 \%$ & $91,93 \%$ & $0,04 \%$ \\
\hline RCD & $3,58 \%$ & $10,42 \%$ & $84,75 \%$ & $1,25 \%$ \\
\hline $\begin{array}{c}\text { Solo + } \\
25 \% \text { RCD }\end{array}$ & $5,78 \%$ & $3,28 \%$ & $90,72 \%$ & $0,22 \%$ \\
\hline $\begin{array}{c}\text { Solo + } \\
50 \% \text { RCD }\end{array}$ & $2,72 \%$ & $3,72 \%$ & $92,34 \%$ & $1,22 \%$ \\
\hline
\end{tabular}

\subsection{Análise Mineralógica}

Para análise dos constituintes mineralógicos da amostra de RCD e de Solo com grãos de diâmetros pré-definidos, separou-se uma pequena quantidade do material e com auxilio de uma Lupa Leica EZ4D foi possível visualizar os minerais constituintes da amostra. Observou-se que na fração de RCD (Figura 5) há predominância de grãos de quartzo e de grãos angulosos a muito angulosos. A fração de solo é formada por grãos arredondados a angulosos, sendo um material predominantemente quartzoso (Figura 6).

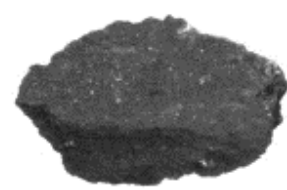

Fig 5-b. Grão de Alvenaria.

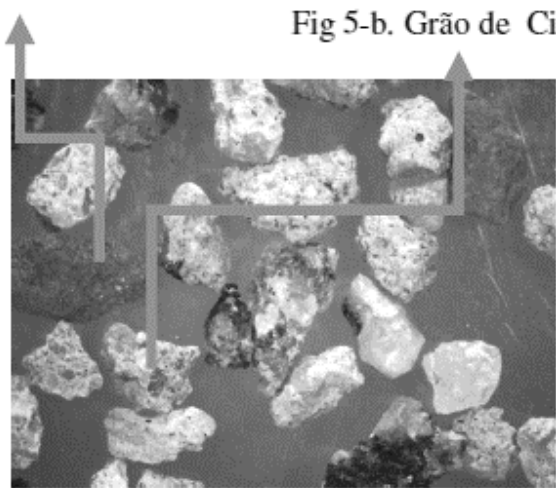

Fig 5. Análise mineralógica do RCD.

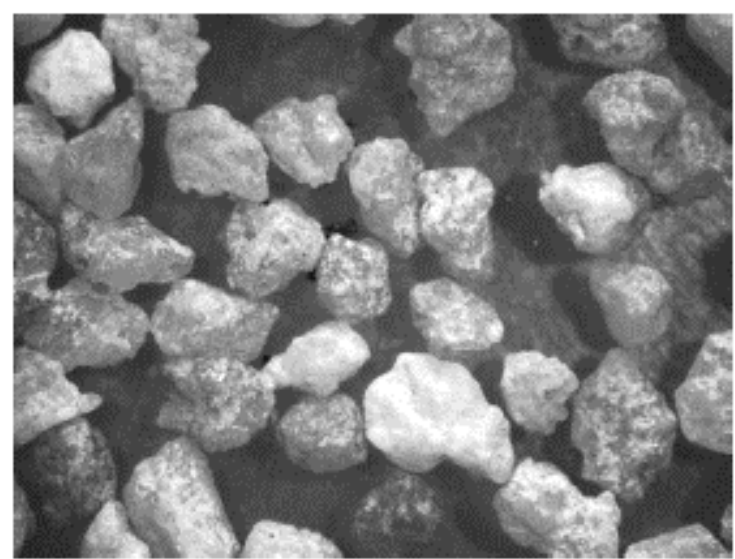

Fig 6. Análise mineralógica do Solo.

\subsection{Ensaio de Compactação}

As curvas de compactação foram obtidas a partir da energia Proctor Normal utilizada em cada uma das amostras. Figura 7 apresenta as curvas e a Tabela 4 mostra os resultados obtidos nos ensaios de compactação.

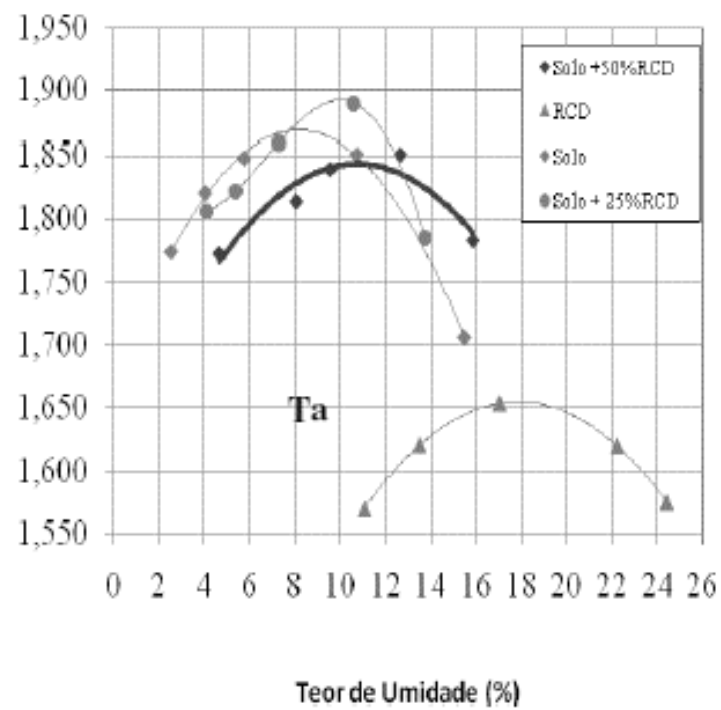

Fig 7. Curvas de compactação das amostras analisadas. 
Tabela 4. Valores obtidos no Ensaio de Compactação.

\begin{tabular}{|c|c|c|}
\hline Amostra & $\begin{array}{c}\text { Umidade } \\
\text { Ótima }(\%)\end{array}$ & $\begin{array}{c}\text { Massa } \\
\text { específica seca } \\
\text { máxima }\left(\mathrm{g} / \mathrm{cm}^{3}\right)\end{array}$ \\
\hline Solo & 8,0 & 1,88 \\
\hline RCD & 18,0 & 1,66 \\
\hline Solo + 25\%RCD & 10,56 & 1,89 \\
\hline Solo + 50\%RCD & 11,0 & 1,84 \\
\hline
\end{tabular}

\subsection{Resistência à compressão dos corpos-de prova cilíndricos}

Os corpos-de-prova foram retirados da câmara úmida após o período de 07 e 28 dias de cura e foram encaminhados a ECOL (Empresa de Consultoria Ltda) onde, antes do ensaio de compressão, foram imersos em água durante 4 horas, de acordo com a NBR 12025 [16]. Apresentam-se na Tabela 5 os resultados obtidos no ensaio de compressão simples.

Tabela 5. Resistência à compressão dos corpos-deprova cilíndricos.

\begin{tabular}{|c|c|c|}
\hline \multirow{2}{*}{ Traço } & \multicolumn{2}{|c|}{$\begin{array}{c}\text { Resistência Média } \\
\text { (MPa) }\end{array}$} \\
\cline { 2 - 3 } & 07 dias & 28 dias \\
\hline Solo + 8\% de cimento & 2,15 & 2,79 \\
\hline $\begin{array}{c}\text { Solo + 8\% de cimento + } \\
25 \% \text { de RCD }\end{array}$ & 2,11 & 2,93 \\
\hline $\begin{array}{c}\text { Solo + 8\% de cimento + } \\
50 \% \text { de RCD }\end{array}$ & 0,81 & 3,11 \\
\hline
\end{tabular}

Verificou-se que a resistência à compressão de ambos os compósitos aumentou de 07 para 28 dias. No entanto, para o compósito com $50 \%$ de RCD, a resistência aos 07 dias foi menor que 2,1 MPa, o que indicou algum erro na moldagem do corpo-de-prova já que aos 28 dias a resistência apresentou significativa elevação.

\section{Conclusão}

O estudo demonstrou que o aproveitamento dos Resíduos da Construção e Demolição na fabricação de tijolos de solo-cimento pode configurar-se numa prática ecologicamente correta e, desse modo, pode contribuir no sentido de reduzir o volume de material descartado na natureza e de reduzir a exploração dos recursos naturais e assim preservar o meio-ambiente. Os resultados indicam que os resíduos de concreto são uma excelente alternativa para melhorar as características dos solos, visando sua aplicação na produção do solo-cimento.
Através da pesquisa foi possível comprovar, através dos ensaios de caracterização física, compactação e resistência à compressão simples, a qualidade do material e a possibilidade de redução no consumo do cimento.

Com o ensaio de granulometria, tanto o solo quanto o RCD, as curvas enquadram-se na faixa de areia, pois não apresentam LL e LP e, tanto o ensaio de densidade real quanto a análise mineralógica confirmam este resultado que é típico de material arenoso com grande quantidade de quartzo e presença de mica, muscovita e biotita.

Quanto às propriedades tecnológicas, verificou-se que as misturas nas proporções de $25 \%$ e $50 \%$ atenderam às especificações para o emprego como solo-cimento. Entretanto, os corpos-de-prova com cura de 07 dias e com adição de $50 \%$ de RCD não atingiu o valor mínimo recomendado pela norma $(2,1 \mathrm{MPa})$, possivelmente por um erro de moldagem do mesmo, já que aos 28 dias ele apresentou uma resistência superior a 2,1 $\mathrm{MPa}$. Os demais ensaios mostraram que a quantidade de cimento a ser adicionada foi de $8 \%$ em massa, permitindo desta forma ao solo-cimento atingir resistência à compressão simples mínima de 2,1 MPA aos 07 dias de cura.

Diante da análise dos dados, observou-se que o emprego de Resíduo da Construção e Demolição reciclado apresenta-se como uma eficiente alternativa no sentido de diminuir o volume de material que, após ser rejeitado pelas obras, acaba muitas vezes sendo descartado de forma inadequada e prejudicando a natureza.

\section{Agradecimentos}

A realização dessa pesquisa só foi possível devido a enorme ajuda do laboratorista do Laboratório de Mecânica dos Solos da Escola Politécnica de Pernambuco, Fábio Ferreira, que esteve presente na execução de todos os ensaios. Agradeço também ao bolsista Felipe Santana do Laboratório de Geologia da UFPE, a Empresa de consultoria Ltda (ECOL) pela ajuda e atenção e, em especial, a Prof ${ }^{a}$ Kalinny Lafayette por todos os seus atos como orientadora e amiga.

\section{Referências}

[1] JOHN, V. M. Reciclagem de resíduos na construção civil: contribuição à metodologia de pesquisa e desenvolvimento. 2000. $102 \mathrm{f}$. Tese (Livre - Docência) - Escola Politécnica, Universidade de São Paulo, São Paulo, 2000. 
PORTLAND - ABCP. Dosagem das misturas de solocimento: normas de dosagem e métodos de ensaio. São Paulo-SP, 1999. ABCP, ET-35, 51p.

[3] ANDRADE FILHO, J. Reforço de solos com a utilização de tubulões em solo-cimento. Dissertação (Mestrado) - Escola de Engenharia de São Carlos. São Carlos, $1989,190 \mathrm{p}$

[4] FERRAZ, A. L. N. Análise da adição de resíduos de argamassa de cimento em tijolos prensados de solo-cimento.2004. 97 f. Dissertação (Mestrado) - Faculdade de Engenharia, Universidade Estadual Paulista "Júlio de Mesquita Filho", Ilha Solteira, 2004.

[5] SEGANTINI, A. A. S. Utilização de solo-cimento plástico em estacas escavadas com trado mecânico em Ilha Solteira (SP). 2000. 176 f. Tese (Doutorado) - Faculdade de Engenharia Civil, Universidade Estadual de Campinas, Campinas, 2000.

[6] BITAR, O. Y. Desafio a sustentabilidade ambiental da mineração e uso de agregados naturais em áreas urbanas. In: SEMINÀRIO DESENVOLVIMENTO SUSTENTÁVEL E A RECICLAGEM NA CONSTRUÇÃO CIVIL, 2, 1999. São Paulo. Anais... São Paulo: Ibracon, 1999.

[7] CONAMA - CONSELHO NACIONAL DE MEIO AMBIENTE (2002). Resolução n ${ }^{\circ} 307$ de 5 de julho de 2002. Estabelece diretrizes, critérios e procedimentos para a gestão dos resíduos da construção. Diário Oficial da República Federativa do Brasil.

[8] PINTO, T. P. Resíduos de construção civil Nova legislação permite rápido avanço para normas técnicas e novas soluções. In: ASSEMBLÉIA NACIONAL DA ASSEMAE, 34, 2004. Caxias do Sul. Anais... Caxias do Sul: ASSEMAC, 2004.

[10] ASSOCIAÇÃO BRASILEIRA DE NORMAS TÉCNICAS. NBR 6508: Grãos de solo que passam na peneira de $4,8 \mathrm{~mm}$ - Determinação da massa específica. Rio de Janeiro, 1984. 7 p.

[11] ASSOCIAÇÃO BRASILEIRA DE NORMAS TÉCNICAS. NBR 7181: Solo - Análise granulométrica. Rio de Janeiro, 1984. 13 p.

[12] ASSOCIAÇÃO BRASILEIRA DE NORMAS TÉCNICAS. NBR 6459: Solo- Determinação do limite deliquidez. Rio de Janeiro, 1984. 6 p.

[13] ASSOCIAÇÃO BRASILEIRA DE NORMAS TÉCNICAS. NBR 7180: Solo - Determinação do limite de plasticidade. Rio de Janeiro, 1984. 3 p.

[14] ASSOCIAÇÃO BRASILEIRA DE NORMAS TÉCNICAS. NBR 7182: Solo - Ensaio de compactação. Rio de Janeiro, 1986. 10 p.

[15] ASSOCIAÇÃO BRASILEIRA DE NORMAS TÉCNICAS. NBR 12025: Solo-cimento - Ensaio de compressão simples de corpos-de-prova cilíndricos. Rio de
Janeiro, 1990. 2 p.

[16] ABNT - Associação Brasileira de Normas técnicas. NBR15115: Agregados reciclados de resíduos sólidos daconstrução civil - execução de camadas de pavimentação - Procedimentos. 10p Rio de Janeiro, 2004. 